\title{
Computerized tomography scan findings of a patient with severe enterocolitis associated with the coronavirus disease 2019: a case report
}

Katsunari Takifuji ( $\square$ takifuji@saiseikai-arida.jp )

Saiseikai Arida Hospital https://orcid.org/0000-0002-1776-001X

Hiroshi Terasawa

Saiseikai Arida Hospital

Masami Oka

Saiseikai Arida Hospital

Masaki Sahara

Saiseikai Arida Hospital

Tomoko Hara

Saiseikai Arida Hospital

Hidekazu Itoh

Saiseikai Arida Hospital

\section{Case Report}

Keywords: New coronavirus, COVID-19 enterocolitis, CT findings

Posted Date: April 3rd, 2020

DOI: https://doi.org/10.21203/rs.3.rs-21006/v1

License: (9) (i) This work is licensed under a Creative Commons Attribution 4.0 International License.

Read Full License 


\section{Abstract}

Background: Currently, there is no available study about the occurrence of enterocolitis associated with the coronavirus disease 2019 (COVID-19) among adults.

Case presentation: A 56-year-old man had lower abdominal pain, distension, diarrhea, and bloody stool. Moreover, the patient presented with fever and general fatigue. Laboratory examination did not reveal leukocytosis nor neutrophilia. However, the patient's C-reactive protein level increased to 4.9 (normal range: $0.0-0.3) \mathrm{mg} / \mathrm{dL}$. Both sputum and stool cultures had normal results. However, abdominal computed tomography (CT) scan revealed wall thickness mainly in the submucosal layer of the left part of the large intestine. Thus, real-time polymerase chain reaction test of throat swabs was performed for the diagnosis of COVID-19, and positive results were obtained.

Conclusions: We report the first case of enterocolitis correlated to COVID-19, and the patient had positive abdominal CT scan findings. This imaging modality could be effective for the diagnosis of enterocolitis associated with COVID-19.

\section{Background}

In December 2019 in Wuhan, China, several patients infected with the coronavirus disease 2019 (COVID19) presented with pneumonia [1]. Recent studies have revealed that COVID-19 spread from human to human mainly via droplet and contact transmission. The incubation period is generally $2.1-11.1$ days. However, it can last up to 14 days [2-4]. Fever, fatigue, and dry cough are the main symptoms [5], but few patients presented with hemoptysis and diarrhea [6].

The diagnosis of COVID-19 is generally diagnosed via real-time polymerase chain reaction (RT-PCR) test of throat swabs $[7,8]$. However, this test may obtain false-negative results due to the use of insufficient viral materials, limitations in sample collection time, and technical errors during the swab procedure. Previous radiographic studies have shown that chest computed tomography (CT) scan has a fundamental role in the evaluation of this disease [9], and typical images reveal multiple ground glass opacities and patchy consolidations in the bilateral lung field [10].

Currently, there is no study about enterocolitis associated with COVID-19 among adults [11], and information about this infection is limited. Herein, we report the first case of enterocolitis correlated to COVID -19 , and the patient had positive abdominal CT scan findings. Thus, this imaging modality could be effective for the diagnosis of enterocolitis associated with COVID-19.

\section{Case Presentation}

A 56-year-old man living in Wakayama City presented with fever $\left(37^{\circ} \mathrm{C}-38.8^{\circ} \mathrm{C}\right)$ and general fatigue. Five days after the onset of symptoms, the patient presented with lower abdominal pain, distension, diarrhea, and bloody stool. In terms of respiratory symptoms, he only had mild cough. The rapid influenza 
diagnostic tests had negative results. However, the patient still presented with the symptoms. Thus, chest and abdominal CT scans were performed 8 days after the onset of symptoms, followed by laboratory examination and sputum and stool cultures. Then, he was admitted to a respiratory medical center. His laboratory examination did not reveal leukocytosis or neutrophilia. However, his C-reactive protein level increased to 4.9 (normal range: $0.0-0.3$ ) $\mathrm{mg} / \mathrm{dL}$. Both sputum and stool cultures had normal results. However, chest CT scan revealed patchy/punctate ground glass opacities and patchy consolidations in the bilateral lung field (Fig. 1). Meanwhile, abdominal CT scan revealed wall thickness mainly in the submucosal layer of the left part of the large intestine. In addition, the density around the intestinal wall was elevated due to parenchymal inflammation (Figs. 2,3).

The patient was then diagnosed with allergic pneumonitis and enterocolitis. Thus, he received a single dose of intravenous corticosteroid and electrolyte and fluid replacement therapy. His digestive symptoms and fever disappeared on day 2 from admission (10 days after the onset).

On 4 day from admission (12 days after the onset), RT-PCR test of throat swabs was performed, and positive results were obtained, because of a co-worker developing the similar chest CT findings for the same period.

There is no subsequent relapse of the symptoms, and the patient was then discharged on day 8 from admission (16 days after the onset of COVID-19). Then, two RT-PCR tests were performed, and both tests had negative results.

\section{Discussion}

COVID-19 can spread from human to human mainly via droplet and contact transmission. Thus, a rapid and accurate diagnosis is required to stop the outbreak, and the prevention and control of nosocomial infection and disease management are also important.

The common symptoms at the onset of illness are fever, dry cough, and dyspnea, which are indicative of pneumonia, and the general symptoms include muscle ache and fatigue [1, 6]. The less common symptoms are sputum production, confusion, and headache. A few individuals present with abdominal symptoms, such as diarrhea, nausea, and vomiting, and hemoptysis [12]. Moreover, approximately $39.6 \%$ of individuals with COVID-19 present with digestive symptoms based on recent reports [13], and this number will gradually increase.

The diagnosis of COVID-19 is generally diagnosed via RT-PCR test of throat swab. However, this test may obtain false-negative results due to the use of insufficient viral materials, limitations in sample collection time, and technical errors during the swab procedure [14]. By contrast, CT scan plays a fundamental role in the evaluation of this disease $[9,15]$. Some studies have shown the efficacy of chest CT scan in obtaining an accurate and rapid diagnosis of COVID-19 [16]. The specific features of COVID19 are multifocal and rapid changes, including patchy/punctate ground glass opacities and patchy consolidations along the bronchial bundle or sub pleural lungs $[17,18][19]$. 
Viral enterocolitis is usually caused by the norovirus, rotavirus, and cytomegalovirus. However, there are no studies showing that this condition is associated with the coronavirus. Herein, we present a rare case of enterocolitis correlated to COVID-19 in a patient who presented with mild cough. Chest and abdominal CT scans were performed. Results revealed wall thickness mainly in the submucosal layer of the left part of the large intestine and a high-density area around the intestinal wall, and pneumonia in the bilateral lung field was also observed. Enterocolitis caused by bacteria is characterized by preferential localization and severe submucosal layer thickness with specific CT scan findings of the giraffe coat sign. However, there is no change around the intestinal wall (Fig. 3) [20,21]. Thus, the ground glass high-density area around the intestinal wall is a specific feature that represents parenchymal inflammation caused by immunoreaction and production of cytokines in COVID-19 [22].

\section{Conclusion}

Herein, we report the first case of enterocolitis associated with COVID-19, and the patient had positive abdominal CT scan findings. Thus, this imaging modality could be effective for the diagnosis of enterocolitis correlated to COVID-19.

\section{List Of Abbreviations}

coronavirus disease 2019: COVID-19

real-time polymerase chain reaction: RT-PCR

computed tomography: CT

\section{Declarations}

Ethics approval and consent to participate: The case report has been granted an exemption from requiring ethics approval by research ethics committee of Saiseikai Arida Hospital, so this case report was conducted in accordance with the Helsinki Declaration.

Consent for publication: We informed and obtained written consent from the patient to publish this case report. Written informed consent for publication of these clinical details and clinical images was obtained from the patient. A copy of the consent form is available for review by the Editor of this journal.

Availability of data and materials: The datasets used and/or analysed during the current study are available from the corresponding author on reasonable request.

Competing interests: There are no conflicts of interest to declare.

Funding: Not applicable 
Authors' contributions: KT was a major contributor in writting the manuscript and a chief of the conception and design of the work, and $\mathrm{HT}, \mathrm{MO}, \mathrm{MS}$ had made contribution as a co-worker. TH had made contribution to the acquisition of this patient's data, and $\mathrm{HI}$ had made contribution as a co-worker and a supervisor. All authors read and approved the final manuscript.

Acknowledgements: The authors would like to thank Enago (www.enago.jp) for the English language review.

\section{References}

1.Chen N, Zhou M, Dong X, Qu J, Gong F, Han Y, et al. Epidemiological and clinical characteristics of 99 cases of 2019 novel coronavirus pneumonia in Wuhan, China: a descriptive study. Lancet. 2020;395(10223):507-13. Epub 2020/02/03. doi: 10.1016/S0140-6736(20)30211-7. PubMed PMID: 32007143.

2.Backer JA, Klinkenberg D, Wallinga J. Incubation period of 2019 novel coronavirus (2019-nCoV) infections among travelers from Wuhan, China, 20-28 January 2020. Euro Surveill. 2020;25(5). Epub 2020/02/13. doi: 10.2807/1560-7917.ES.2020.25.5.2000062. PubMed PMID: 32046819.

3.Linton NM, Kobayashi T, Yang Y, Hayashi K, Akhmetzhanov AR, Jung SM, et al. Incubation Period and Other Epidemiological Characteristics of 2019 Novel Coronavirus Infections with Right Truncation: A Statistical Analysis of Publicly Available Case Data. J Clin Med. 2020;9(2). Epub 2020/02/23. doi: 10.3390/jcm9020538. PubMed PMID: 32079150.

4.Ki M, nCo VT. Epidemiologic characteristics of early cases with 2019 novel coronavirus (2019-nCoV) disease in Republic of Korea. Epidemiol Health. 2020:e2020007. Epub 2020/02/10. doi:

10.4178/epih.e2020007. PubMed PMID: 32035431.

5.Wang D, Hu B, Hu C, Zhu F, Liu X, Zhang J, et al. Clinical Characteristics of 138 Hospitalized Patients With 2019 Novel Coronavirus-Infected Pneumonia in Wuhan, China. JAMA. 2020. Epub 2020/02/08. doi: 10.1001/jama.2020.1585. PubMed PMID: 32031570.

6.Chen L, Liu HG, Liu W, Liu J, Liu K, Shang J, et al. [Analysis of clinical features of 29 patients with 2019 novel coronavirus pneumonia]. Zhonghua Jie He He Hu Xi Za Zhi. 2020;43(0):E005. Epub 2020/02/07. doi: 10.3760/cma.j.issn.1001-0939.2020.0005. PubMed PMID: 32026671.

7.Corman VM, Landt O, Kaiser M, Molenkamp R, Meijer A, Chu DK, et al. Detection of 2019 novel coronavirus (2019-nCoV) by real-time RT-PCR. Euro Surveill. 2020;25(3). Epub 2020/01/30. doi: 10.2807/1560-7917.ES.2020.25.3.2000045. PubMed PMID: 31992387; PubMed Central PMCID: PMCPMC6988269.

8.Zou L, Ruan F, Huang M, Liang L, Huang H, Hong Z, et al. SARS-CoV-2 Viral Load in Upper Respiratory Specimens of Infected Patients. N Engl J Med. 2020. Epub 2020/02/20. doi: 10.1056/NEJMc2001737. 
9.Ai T, Yang Z, Hou H, Zhan C, Chen C, Lv W, et al. Correlation of Chest CT and RT-PCR Testing in Coronavirus Disease 2019 (COVID-19) in China: A Report of 1014 Cases. Radiology. 2020:200642. Epub 2020/02/27. doi: 10.1148/radiol.2020200642. PubMed PMID: 32101510.

10.Chung M, Bernheim A, Mei X, Zhang N, Huang M, Zeng X, et al. CT Imaging Features of 2019 Novel Coronavirus (2019-nCoV). Radiology. 2020:200230. Epub 2020/02/06. doi: 10.1148/radiol.2020200230. PubMed PMID: 32017661.

11.Moscovici O, Chany C, Lebon P, Rousset S, Laporte J. [Association of coronavirus infection with hemorrhagic enterocolitis in newborn infants]. C R Seances Acad Sci D. 1980;290(13):869-72. Epub 1980/03/31. PubMed PMID: 6248262.

12.Huang C, Wang Y, Li X, Ren L, Zhao J, Hu Y, et al. Clinical features of patients infected with 2019 novel coronavirus in Wuhan, China. Lancet. 2020;395(10223):497-506. Epub 2020/01/28. doi:

10.1016/S0140-6736(20)30183-5. PubMed PMID: 31986264.

13. Han W, Quan B, Guo Y, Zhang J, Lu Y, Feng G, et al. The course of clinical diagnosis and treatment of a case infected with coronavirus disease 2019. J Med Virol. 2020. Epub 2020/02/20. doi:

10.1002/jmv.25711. PubMed PMID: 32073161.

14. Winichakoon P, Chaiwarith R, Liwsrisakun C, Salee P, Goonna A, Limsukon A, et al. Negative Nasopharyngeal and Oropharyngeal Swab Does Not Rule Out COVID-19. J Clin Microbiol. 2020. Epub 2020/02/28. doi: 10.1128/JCM.00297-20. PubMed PMID: 32102856.

15.Xie X, Zhong Z, Zhao W, Zheng C, Wang F, Liu J. Chest CT for Typical 2019-nCoV Pneumonia: Relationship to Negative RT-PCR Testing. Radiology. 2020:200343. Epub 2020/02/13. doi: 10.1148/radiol.2020200343. PubMed PMID: 32049601.

16.Fang Y, Zhang H, Xie J, Lin M, Ying L, Pang P, et al. Sensitivity of Chest CT for COVID-19: Comparison to RT-PCR. Radiology. 2020:200432. Epub 2020/02/20. doi: 10.1148/radiol.2020200432. PubMed PMID: 32073353.

17.Kanne JP. Chest CT Findings in 2019 Novel Coronavirus (2019-nCoV) Infections from Wuhan, China: Key Points for the Radiologist. Radiology. 2020:200241. Epub 2020/02/06. doi:

10.1148/radiol.2020200241. PubMed PMID: 32017662.

18.Pan Y, Guan H, Zhou S, Wang Y, Li Q, Zhu T, et al. Initial CT findings and temporal changes in patients with the novel coronavirus pneumonia (2019-nCoV): a study of 63 patients in Wuhan, China. Eur Radiol. 2020. Epub 2020/02/15. doi: 10.1007/s00330-020-06731-x. PubMed PMID: 32055945.

19.Wang J, Liu J, Wang Y, Liu W, Chen X, Sun C, et al. [Dynamic changes of chest CT imaging in patients with corona virus disease-19 (COVID-19)]. Zhejiang Da Xue Xue Bao Yi Xue Ban. 2020;49(1):0. Epub 
20.Wessling J. [Radiological imaging of acute infectious and non-infectious enterocolitis]. Radiologe. 2018;58(4):302-11. Epub 2018/03/24. doi: 10.1007/s00117-018-0379-3. PubMed PMID: 29569035.

21.Siddiqui J, Campion T, Wei R, Kuzmich S. Clostridium difficile enteritis: diffuse small bowel radiological changes in a patient with abdominal sepsis. BMJ Case Rep. 2018;2018. Epub 2018/01/29. doi: 10.1136/bcr-2017-222209. PubMed PMID: 29374636; PubMed Central PMCID: PMCPMC5786970.

22.Baruah V, Bose S. Immunoinformatics-aided identification of T cell and B cell epitopes in the surface glycoprotein of 2019-nCoV. J Med Virol. 2020. Epub 2020/02/06. doi: 10.1002/jmv.25698. PubMed PMID: 32022276.

\section{Figures}

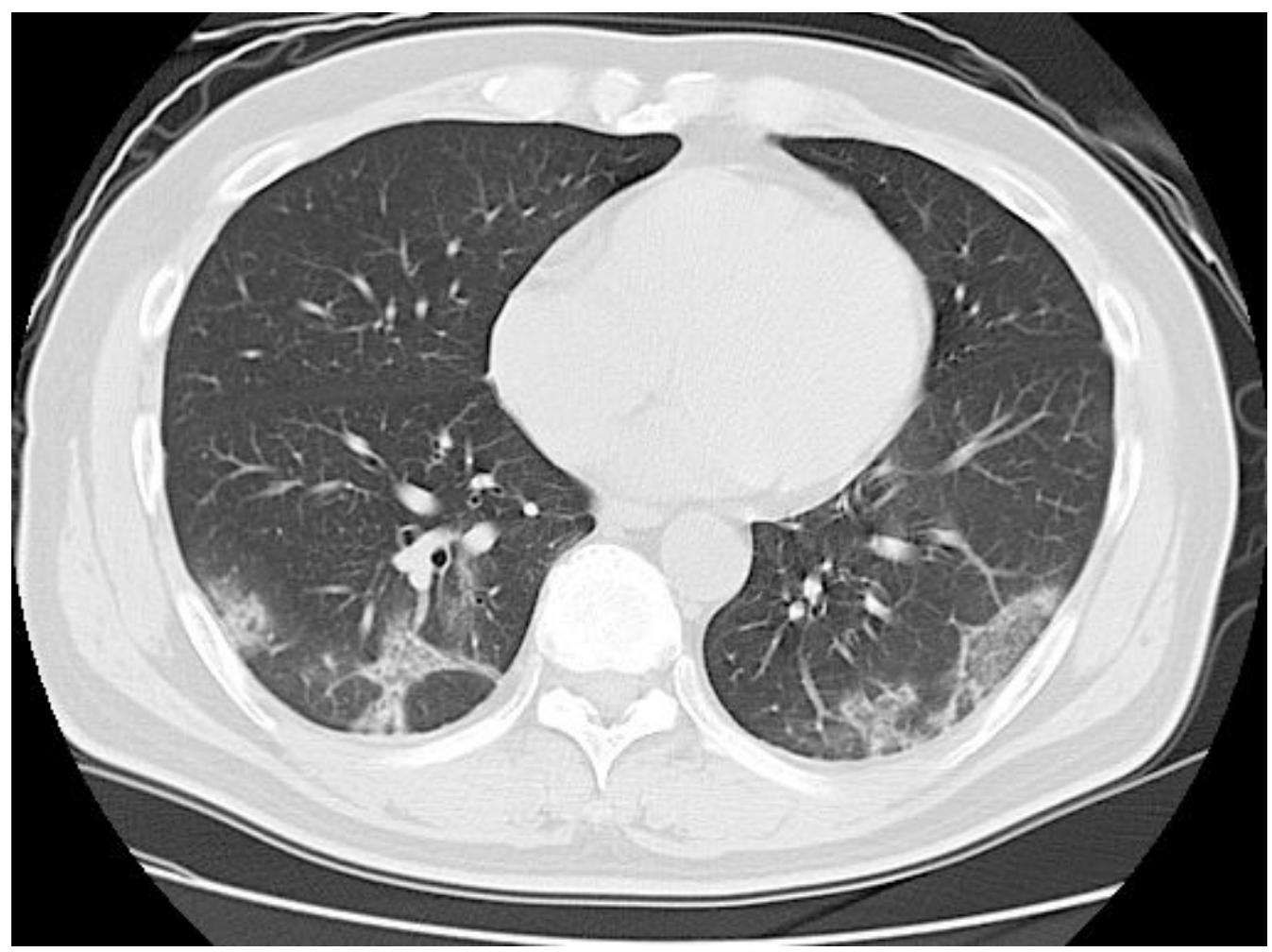

Figure 1

Chest computed tomography scan revealed patchy/punctate ground glass opacities and patchy consolidation in the bilateral lung field. 


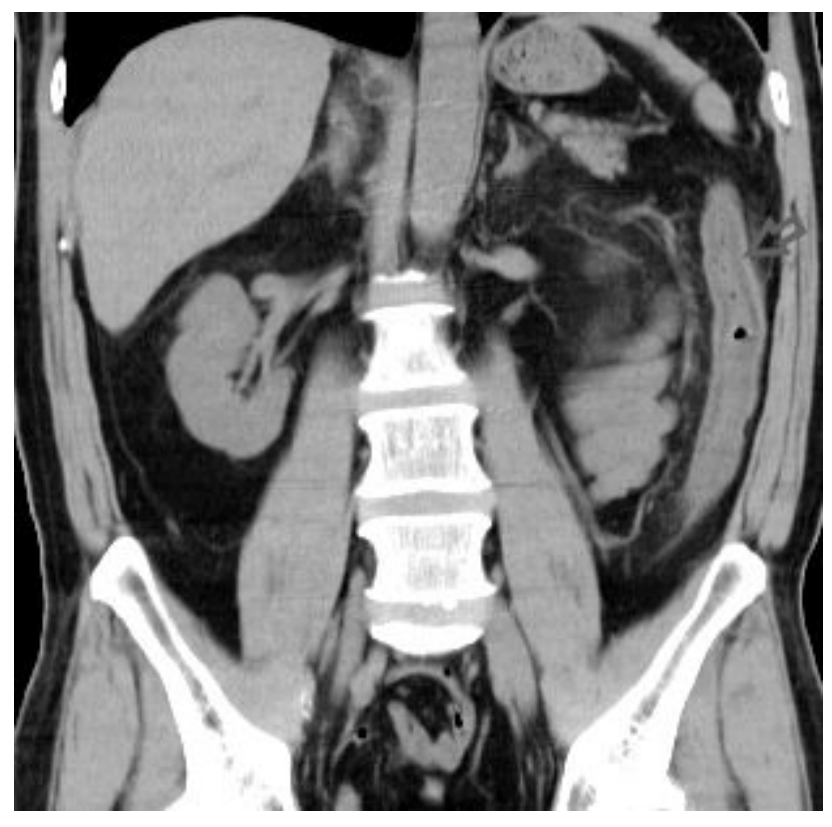

Figure 2

Abdominal computed tomography (CT) scan revealed wall thickness mainly in the submucosal layer (open allow) of the left part of the large intestine.

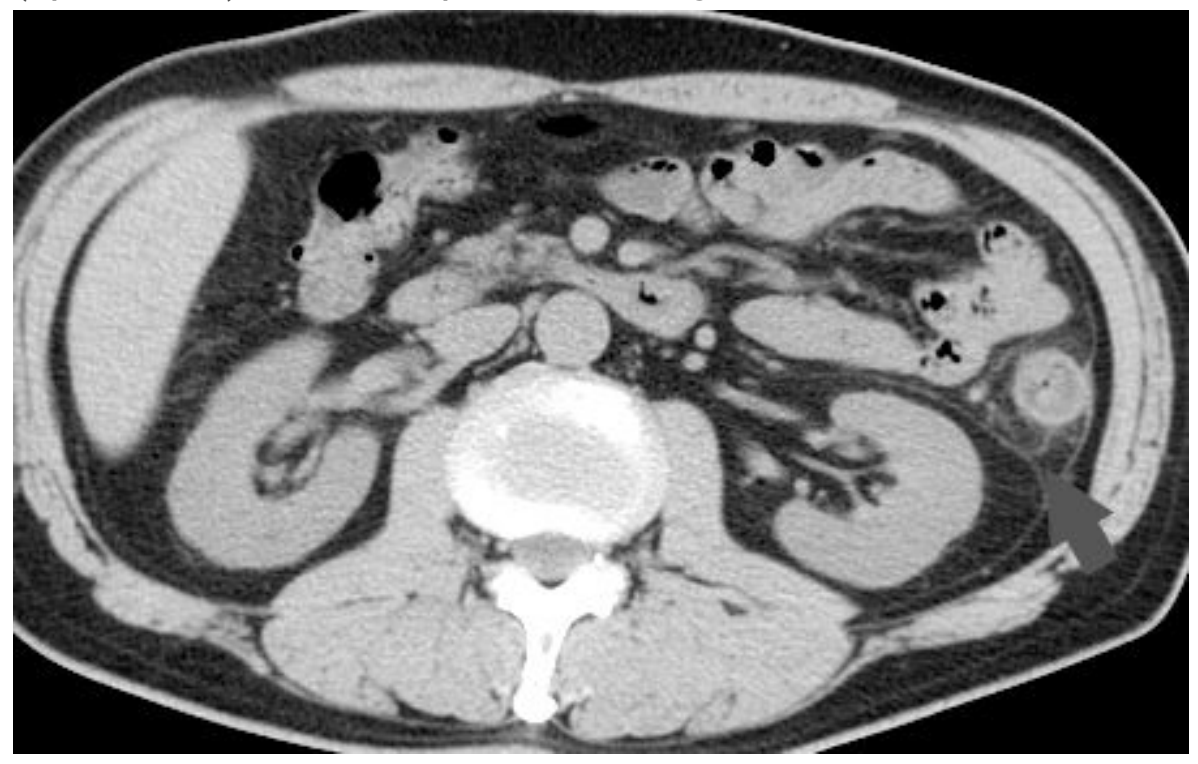

Figure 3

The CT density was high similar to the ground glass around the intestinal wall that represents parenchymal inflammation (closed allow). 


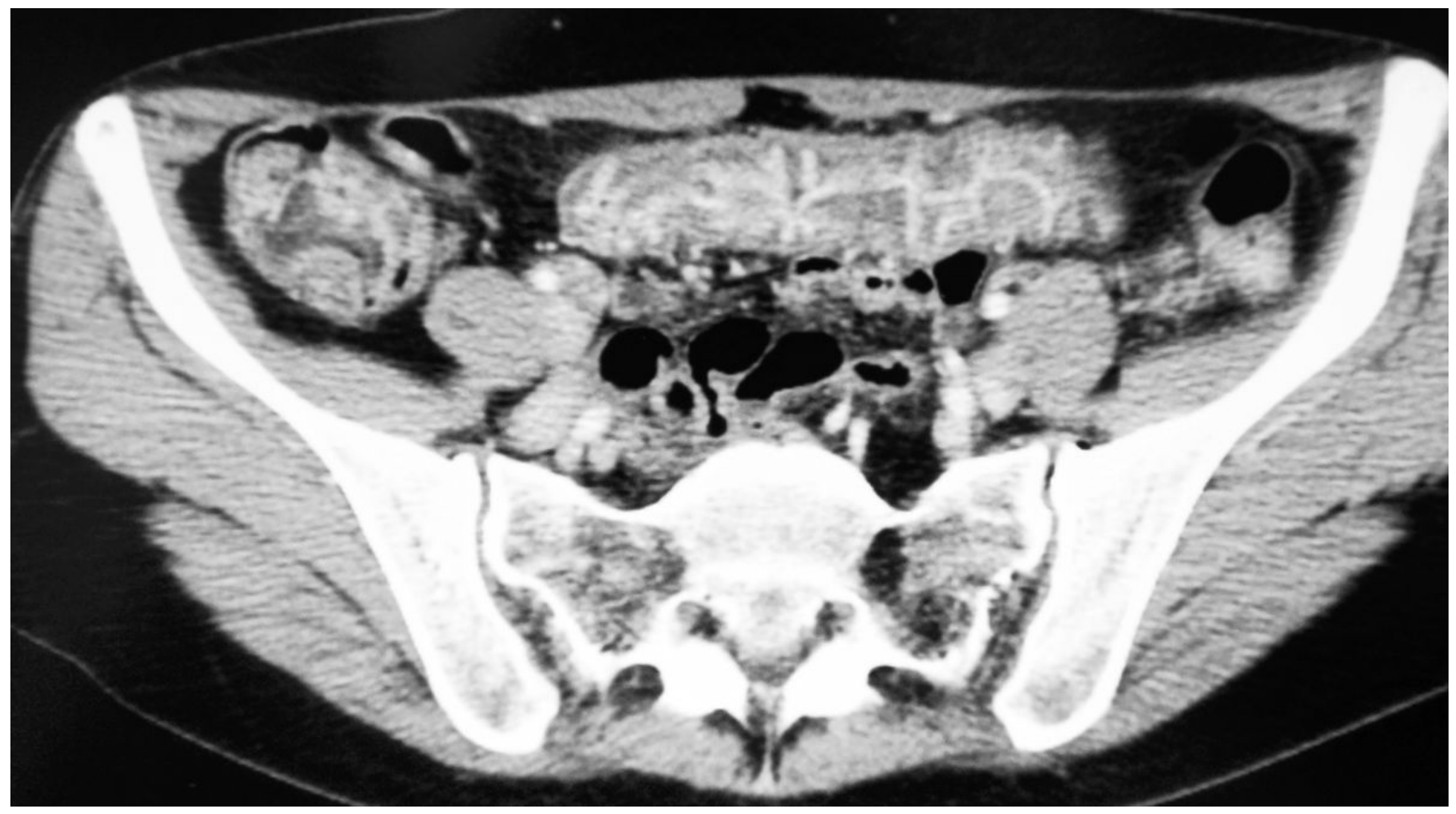

\section{Figure 4}

In enterocolitis caused by Campylobacter jejuni, abdominal computed tomography (CT) scan revealed severe submucosal layer thickness in the right side of the large intestine (giraffe coat sign). However, the density of the mesentery around the intestinal wall was normal.

\section{Supplementary Files}

This is a list of supplementary files associated with this preprint. Click to download.

- CAREchecklistEnglish2013Takifuji.docx 